\title{
Um estudo sobre governança de tecnologia da informação no campus de Frederico Westphalen-RS da Universidade Federal de Santa Maria
}

\section{Information technology governance: a study at the campus of Universidade Federal de Santa Maria - Frederico Westphalen-RS}

\author{
Simone Aparecida Ceratti Bacharel em Sistemas de Informação. Universidade Federal de Santa Maria - \\ Campus Frederico Westphalen (UFSM) - Brasil - simone.ceratti@hotmail.com \\ Cristiano Bertolini Doutor em Ciência da Computação. Universidade Federal de Santa Maria - \\ Campus Frederico Westphalen (UFSM) - Brasil - cristiano.bertolini@ufsm.br \\ Sidnei Renato Silveira Doutor em Ciência da Computação. Universidade Federaç de Santa Maria - \\ Campus Frederico Westphalen (UFSM) - Brasil - sidneirenato.silveira@gmail.com
}

\section{RESUMO}

A Governança de Tecnologia da Informação (TI) tem-se tornado importante nas organizações, pois facilita a tomada de decisões por meio do alinhamento da área de TI com a área de negócio (foco) da organização. No entanto, a governança de TI é um processo lento e caro em termos de infraestrutura e recursos. Neste contexto, este artigo apresenta um estudo de caso, utilizando a metodologia de pesquisa qualitativa-quantitativa, sobre a governança de TI em um campus avançado da Universidade Federal de Santa Maria (UFSM-FW) e propõe uma reorganização dos serviços de TI com suporte em ferramentas de código aberto. $\mathrm{O}$ estudo demonstrou a necessidade de uma reestruturação do setor de Tl e que o apoio de ferramentas para a automação pode tornar a UFSM mais gerenciável.

Palavras-chave: Governança. Framework. Ferramenta.

\begin{abstract}
Governance of Information Technology (IT)has become important in organizations because it facilitates decision-making through the alignment of IT with the area of business (the focus) of the organization. However, IT governance is a slow and expensive process in terms of infrastructure and resources. In this context, this paper presents a case study about IT governance in an advanced campus of the Federal University of Santa Maria (UFSM-FW), by using qualitative-quantitative research methodology. The paper also proposes a reorganization of the IT services with support to the open source tools. The study demonstrated the necessity of a restructuring of the IT sector and that the support of the tools for automation can make UFSM more manageable.
\end{abstract}

Keywords: IT Governance. Framework. Tool.

Recebido em 08/10/2018. Aprovado em 13/02/2019. Avaliado pelo sistema double blind peer review. Publicado conforme normas da ABNT. http://dx.doi.org/10.22279/navus.2019.v9n4.p10-29.862 


\section{INTRODUÇÃO}

A Governança Corporativa é um "sistema pelo qual organizações são dirigidas, monitoradas e incentivadas, envolvendo todas as áreas da empresa com a área de TI" (MANCINI; ROSINI, 2013). A governança corporativa fundamenta-se em quatro pilares: 1) transparência: deixando transparecer as ações às partes interessadas; 2 ) equidade: onde o tratamento é justo a todos na organização; 3 ) prestação de contas: prestando contas e assumindo os resultados para suporte dos responsáveis pela área de TI da organização; 4) responsabilidade corporativa: zela pela organização para que tenha longevidade e sustentabilidade (MANCINI; ROSINI, 2013).

As organizações precisam melhorar o gerenciamento das informações que regem sua sobrevivência no mercado, pois essas informações são fundamentais para garantir a integridade das mesmas. A partir dessa necessidade surgiram os modelos de Governança de TI para ajudar as organizações a gerirem suas tecnologias, fornecendo ferramentas e métricas para o alinhamento entre os processos de Tl e os objetivos estratégicos da organização (RODRIGUES, 2005).

A Governança de TI é um instrumento de apoio importante a ser seguido pelas organizações, pois auxilia na tomada de decisões. Uma das principais problemáticas de Governança de TI é a falta de infraestrutura, incluindo pessoas preparadas e disponíveis para tal função. A Governança de Tl oferece diversos benefícios para as organizações, já que uma organização é um conjunto de fatores internos e externos que afetam a mesma diretamente.

A Governança de TI auxilia na tomada de decisão, encontrando uma solução adequada em tempo hábil. Ao analisar a Governança de $\mathrm{Tl}$, verifica-se que um dos problemas no uso é a sua complexidade, pois exige tempo, investimento e recursos humanos. Porém, quando se analisam os benefícios da Governança de $\mathrm{Tl}$, verifica-se que os gastos necessários são amplamente recuperados quando se têm dados relevantes para poder tomar decisões. A Governança de TI é motivada por: TI como prestadora de serviços, integração tecnológica, segurança da informação, dependência do negócio em relação à $\mathrm{Tl}$, marcos de regulação e ambiente de negócio (FERNANDES; ABREU, 2012).

Neste contexto, este artigo propõe uma análise da Governança de TI na Universidade Federal de Santa Maria (UFSM), campus de Frederico Westphalen - RS, e sugere o uso de ferramentas baseadas em software livre, mais precisamente a ferramenta CITSMART. A aplicação de uma ferramenta baseada em software livre ameniza os custos, viabilizando a implantação de Governança de TI na universidade, por ser um órgão público com recursos limitados.

Para dar conta desta proposta, o presente artigo está organizado da seguinte forma: a seção 2 apresenta alguns trabalhos relacionados, sendo citadas quatro pesquisas para acompanhamento em processos de implantação de Governança de TI. A seção 3 apresenta uma breve descrição de Governança e uma ferramenta de auxílio para a realização de Governança de TI, a ferramenta CITSMART. A seção 4 descreve a utilização de Governança de TI no campus de Frederico Westphalen - RS da UFSM, com análise de serviços de Help Desk e gestão de incidência, analisando dados existentes no campus. A seção 5 descreve o desenvolvimento de uma proposta de Governança de TI, mostrando um mapeamento de serviços usando ITIL, um portfólio de serviços e um catálogo de serviços.

\section{TRABALHOS RELACIONADOS}

Mancini e Rosini (2013) desenvolveram um estudo de caso em uma instituição financeira de médio porte, descrevendo o processo de implantação de Governança de TI, analisando documentos, aplicando o método da observação participante. A organização financeira utilizou um modelo de boas práticas de Governança Corporativa publicado pelo IBGC (Instituto Brasileiro de Governança Corporativa). A organização era dividida em três áreas: Desenvolvimento de Sistemas, Suporte Técnico e Processos, com problemas de imagem da área de $\mathrm{Tl}$, projetos com altos custos e baixo retorno de investimento e não alinhamento das estratégias de negócios com as estratégias de TI. Foi contratada uma consultoria especializada para alcançar o 
nível 3 de maturidade (Definido) sendo que, até o momento, a organização estava no nível 2 (Repetitivo), simplificando processos, monitorando, mensurando resultados e detectando desvios.

$\mathrm{O}$ auge da pesquisa foi a conquista do nível 3 usando o framework COBIT (Control Objectives for Information and Related Technology). A partir de então foram observadas mudanças na cultura da organização. Diferindo do estudo realizado na UFSM, que é uma instituição de ensino pública, em que foram estudadas ferramentas já existentes na universidade, usando como norteador o framework ITIL (Information Technology Infrastructure Library), o estudo relacionado implantou a Governança de TI em uma instituição financeira que basicamente busca o lucro, usando frameworks e boas práticas de Governança Corporativa publicadas pelo IBGC.

Neves (2013) realizou um estudo de caso em uma empresa pública, criada para gerir outras empresas federais, onde são oferecidos serviços como consultorias, desenvolvimento, suporte, provimento, treinamento e administração. Para a coleta de dados foram utilizadas entrevistas, análise de relatórios e planilhas, comparando dados obtidos com o framework de boas práticas do ITIL, com a coleta de dados, análise e resultados, aplicados no corpo técnico, identificando problemas do dia a dia. Finalizando o estudo, foi realizada uma análise e amostra aos técnicos dos cinco problemas mais frequentes, buscando soluções para os mesmos. Após, foi realizado um diagnóstico, com identificação dos problemas, identificando informações de falhas existentes e as soluções, levantando dados numéricos para quantificar informações. Depois de identificados os problemas, foram relacionados os cinco mais frequentes, transcrevendo-os de forma a facilitar a quantificação de informações, permitindo identificar deficiências nos processos de diagnósticos.

Morais (2010) realizou um estudo de caso usando uma abordagem qualitativa, interagindo apenas com os principais gestores de TI. Essa pesquisa foi de natureza exploratória. Primeiramente foi realizada uma pesquisa bibliográfica para levantamento de informações sobre a aplicação de Governança de TI, Governança Corporativa e seus principais frameworks. Após, foi realizada uma pesquisa de campo para identificação de problemas, coletando informações com os gerentes da organização, relacionando estas informações com os frameworks de boas práticas e identificando benefícios e dificuldades. A partir disso, foram determinadas ações a serem tomadas permitindo, dessa forma, alinhar a estratégia de TI com a estratégia da organização, realizando um plano de ação designando gestores para realizar as ações. Após a análise de dados, foi construído o mapa estratégico de TI, identificando melhores práticas para cada área da organização, visando à melhoria na cultura da organização. Os frameworks COBIT e ITIL foram instrumentos viabilizadores, orientando as ações para desenvolver instrumentos de avaliação básica e na orientação de práticas na organização, aprimorando a gestão estratégica da organização. O PMBoK também fez parte do processo de melhoria, dando apoio aos líderes do negócio. O framework COBIT foi um dos principais norteadores neste estudo, enquanto que para o estudo de caso na UFSM, o framework ITIL foi o fundamentador da pesquisa disponibilizando suporte para a análise e a descrição de dados levantados, identificando o portfólio de serviços.

Masson, Pereira e Souza Neto (2014) realizaram uma pesquisa na Administração Pública. O objetivo foi o de avaliar, junto a órgãos da Administração Pública Federal, o alinhamento da Governança de TI com a Governança Corporativa. Esta investigação utilizou a abordagem quantitativa. Os dados referentes à Governança Corporativa e de $\mathrm{Tl}$, além dos principais modelos de governança, foram obtidos em pesquisa documental. Foram aplicados instrumentos de coleta de dados: pesquisa em bases de dados, documentos organizacionais e questionários semifechados. A pesquisa foi respondida por responsáveis da área de TI. Após a análise, os autores concluíram que a Governança de TI era pouco ou nada aplicada como auxílio na tomada de decisão. Os resultados obtidos na pesquisa remetem a uma baixa atuação da alta administração na Governança de TI nas instituições pesquisadas. O estudo relacionado difere-se do realizado na UFSM campus de Frederico Westphalen, por este ter usado como frameworkas boas práticas do ITIL e do ISO/IEC38500 como norteadores para analisar e alinhar TI à ferramenta de Help Desk da organização, enquanto os autores, em seu estudo, buscam o alinhamento da Governança de TI à Governança Corporativa.

Raposo, Leitão e Paço (2006) desenvolveram um estudo dos benefícios de utilizar ferramentas de benchmarking em universidades, destacando que as universidades têm de ser entidades que promovam a sustentabilidade, principalmente devido ao aumento de custo para manutenção das mesmas, a redução de 
financiamento público e o aumento de alunos nas universidades. Dessa forma, neste artigo foi demonstrada a importância do benchmarking para as universidades, pois ajuda na avaliação e detecção de problemas organizacionais, desenvolvendo a área de governança pró-sustentável. Este estudo estava orientado para uma estratégia de implementar a criação de sistemas de governança, baseando no desenvolvimento de projetos simples, mensuráveis, responsáveis, realistas e relacionados às equipes. A abordagem foi baseada na implementação de práticas de marketing público, que são baseadas na mistura de projetos inteligentes com uma abordagem competitiva, por meio do uso de ferramentas de benchmarking direcionadas para uma implementação eficaz. O benchmarking é um processo de aprendizagem que está estruturado de forma a tornar possível avaliar os produtos, serviços e os pontos fortes e fracos de uma organização, visando o próprio aperfeiçoamento e autocontrole. Envolve um processo sistemático, que mede e compara os processos da organização que trabalha com as demais organizações consideradas referências. Por meio desse processo é possível definir papéis e responsabilidades.

\section{MODELOS DE GOVERNANÇA DE TECNOLOGIA DA INFORMAÇÃO}

Nesta seção são apresentados os principais modelos de Governança de TI considerados neste trabalho.

\subsection{Norma ISO/IEC 38500}

A Governança de TI auxilia na administração, integrando TI em todas as áreas da organização, deixando de ser vista como gasto e, sim, como apoio. A ISO/IEC 38500 é uma norma de alto nível, feita para diretores. Motiva o uso da TI como ferramenta de trabalho, pois as organizações precisam da tecnologia para conseguir crescer. Porém, seu custo é significativo e precisa ser usada de forma correta. A governança de $\mathrm{TI}$ envolve, além de recursos físicos, recursos humanos. Por essa razão está sujeita a erros. A ISO/IEC 38500 foi padronizada oferecendo um framework para governança efetiva de Tl, definindo normas e princípios, diferenciando governança de gerência, onde governança atinge todas as áreas da organização e gerência está mais focada aos processos. Entretanto, a governança precisa de gerência, para manter a organização (ISO, 2008).

Na norma ISO/IEC 38500, a Governança de TI é aplicável em qualquer organização de qualquer ramo e tamanho, por ser genérica, tendo com principal objetivo o uso de TI. Nesta norma foram estabelecidos 6 princípios (ISO, 2008):

1) Responsabilidade: define os responsáveis e pelo que serão responsáveis, tendo autonomia na tomada de decisões. Aplicada para indivíduos ou grupo de indivíduos;

2) Estratégia: considera as capacidades atuais de TI, identificando as condições da organização. Deve satisfazer as necessidades atuais e futuras, as estratégias têm que estar alinhadas ao negócio;

3) Aquisição: as aquisições são realizadas com base em análises apropriadas, com tomada de decisão clara, levando em conta custos, benefícios e necessidades;

4) Performance: a TI satisfaz as necessidades da organização, trazendo lucro, na busca por atender aos requisitos do negócio, medindo resultados;

5) Conformidade: estar em conformidade com as leis e regulamentos, levando em conta a legislação;

6) Comportamento Humano: respeitar as individualidades de cada um.

Os modelos de negócio devem seguir padrões de como realizar as etapas da governança, voltada para diretores das organizações baseadas em três tarefas: 1) Avaliar: os diretores devem saber o estado atual da organização, avaliando o ambiente em que estão envolvidos, considerando a evolução contínua, analisando necessidades atuais e futuras e qual a vantagem competitiva; 2) Direcionar: os diretores devem delegar atividades para os responsáveis de cada área, gerenciando corretamente, estando em conformidade com a infraestrutura existente e seus especialistas, incentivando a melhoria da cultura organizacional; 3) Monitorar: 
os diretores devem monitorar a TI usando métricas, verificando a conformidade com a lei, usando tarefas dentro dos princípios (ISO, 2008).

\subsection{COBIT}

O COBIT é um guia para a gestão das melhores práticas da TI, voltado para processos e controles. Utiliza um framework que fornece melhores práticas para gerenciamento de processos de TI de uma forma estruturada, gerenciável e lógica, idealizado para atender necessidades da Governança Corporativa, com foco nos requisitos de negócio, utilizando mecanismos de controle e análise de indicadores de desempenho. $\mathrm{O}$ COBIT pode ser utilizado por qualquer empresa, independe das tecnologias empregadas na mesma, não importando se é de pequeno ou grande porte (ISACA, 2012). O COBIT está dividido em quatro domínios:

1) Planejamento e Organização: trata as estratégicas e táticas para que a TI possa contribuir para a realização dos objetivos de negócio;

2) Aquisição e Implementação: determina a estratégia de TI para identificar, qualificar e escolher soluções a serem desenvolvidas ou adquiridas;

3) Entrega e Suporte: verifica os serviços requeridos pelos processos de negócio, para que haja entrega de informações e suporte para as operações em situações inesperadas;

4) Monitoração: monitora os controles da organização de Tl, sendo fundamental a avaliação contínua e regular da qualidade e da conformidade dos controles implantados.

Segundo Isaca (2012), o COBIT é baseado em 5 princípios que permitem que a organização construa um framework de governança e gestão de TI baseado em um conjunto de 7 habilitadores que otimizam investimentos em tecnologia e informação utilizados para o benefício dos interessados:

Princípio 1 - atender às necessidades dos stakeholders: as organizações existem para criar valor para os envolvidos;

Princípio 2 - cobrir a organização de ponta a ponta: os gestores de negócio têm a responsabilidade de tratar a TI como um ativo estratégico, onde a TI é igual aos demais;

Princípio 3 - aplicar um framework único e integrado: integrar todos os conhecimentos existentes em diferentes frameworks;

Princípio 4 - possibilitar uma abordagem holística: o COBIT utiliza 7 viabilizadores (Princípios, Políticas e Frameworks, Processos, Estruturas Organizacionais, Cultura, Ética e Comportamento, Informação, Serviços, Infraestrutura e Aplicações, Pessoas, Habilidades e Competências), que apoiam a governança e a gestão de TI para abordar a organização de uma forma completa;

Princípio 5 - separar a governança da gestão: determinar onde cada área atuará, suas estruturas e propósitos.

\subsection{ITIL}

O ITIL é a junção das melhores práticas para auxiliar organizações, tanto no setor público como no privado, usando as melhores formas para a criação execução e manutenção de serviços, visando entregar valores aos clientes (BALDIN; BALDIN, 2011).

A ITIL teve seu início nos anos 80, para atender a necessidade do governo britânico, onde a insatisfação com a Tl era preocupante. Assim, foi desenvolvido um conjunto de boas práticas para gerenciar a utilização eficiente e responsável dos recursos de $\mathrm{Tl}$, independendo dos fornecedores, sendo aplicável a qualquer organização, respeitando as necessidades específicas de cada uma delas. ITIL é um framework que descreve as melhores práticas no gerenciamento de serviço de $\mathrm{TI}$, fornecendo para a governança de $\mathrm{TI}$ um framework para gerenciamento e controle, focado no uso de métricas e melhoria da qualidade dos serviços. Este framework fornece benefícios para os diretores, aumentando a satisfação dos usuários e clientes, melhorando a tomada de decisão e diminuindo os riscos (CESTARI FILHO, 2011). 


\subsection{CITSMART}

O CITSMART é um software de gestão de TI, que implementa conceitos e técnicas de Governança de TI, com o objetivo de manter a eficiência nos processos de prestação de serviços e promover sua melhoria (CITSMART, 2018). É possível cadastrar e gerenciar serviços e solicitações de chamados de atendimento, de acordo com o tipo de serviço que foi solicitado. A ferramenta permite identificar se o chamado é um incidente ou requisição e a data de criação de tal chamado, a prioridade e o prazo limite para a execução do chamado e, também, o estado que ele se encontra se em execução, encerrado ou em prazo normal de execução.

Esta plataforma de governança corporativa teve sua criação voltada para facilitar a integração entre informação e tecnologia no ambiente organizacional. O CITSMART é uma solução integrada, com capacidade de gerenciar qualquer requisição de serviço ou fluxo de trabalho, com intuito de prover governança por meio da Tecnologia da Informação, fornecendo maior eficácia à gestão dos negócios, fazendo uso de melhores práticas, de estratégia de atuação corporativa e metodologias inovadoras. A ferramenta foi planejada para obedecer aos mais rigorosos critérios exigidos pelo Pink Verify, um selo que endossa ferramentas baseadas nos processos de gerenciamento de Serviços propostos pela ITIL. Os processos da ITIL certificados Pink Verify são: Gerenciamento de Incidente, Cumprimento de Requisição, Gerenciamento do Conhecimento, Gerenciamento de Portfólio, Gerenciamento do Catálogo de Serviços, Gerenciamento de Nível de Serviço, Gerenciamento de Configuração e Ativos de Serviços, Gerenciamento de Mudança, Gerenciamento de Problema e Gerenciamento de Liberação (CITSMART, 2018).

\section{GOVERNANÇA DE TI NA UFSM - CAMPUS FREDERICO WESTPHALEN - RS}

Esta seção apresenta algumas ações de Governança de TI, desenvolvidas na UFSM - campus de Frederico Westphalen - RS. A metodologia empregada neste trabalho foi a realização de um estudo de caso, com análise dos resultados de forma qualitativa e quantitativa. Segundo Yin (2001), os estudos de caso são uma metodologia de pesquisa adequada quando se colocam questões do tipo "como" e "por que". Tais indagações fazem parte do objetivo geral deste trabalho, pois pretendeu-se identificar como a Governança de TI é realizada no campus da UFSM de Frederico Westphalen, além de identificar ferramentas para serem aplicadas para auxiliar as tarefas do setor de TI. Além da observação dos serviços realizados pela equipe de TI da universidade, elaborou-se um instrumento de pesquisa (questionário semiestruturado), visando coletar informações dos alunos, professores e servidores técnico-administrativos, com relação aos serviços na área de TI oferecidos no campus.

\subsection{Serviço de Help Desk}

A Figura 1 apresenta a interface do sistema de Help Desk usado pelo setor de TI da UFSM campus de Frederico Westphalen - RS. Nesta interface são solicitados os dados do usuário, do local onde o problema está instaurado, além da descrição do problema. 
Figura 1 - Interface do Sistema de Help Desk usado na UFSM campus FW

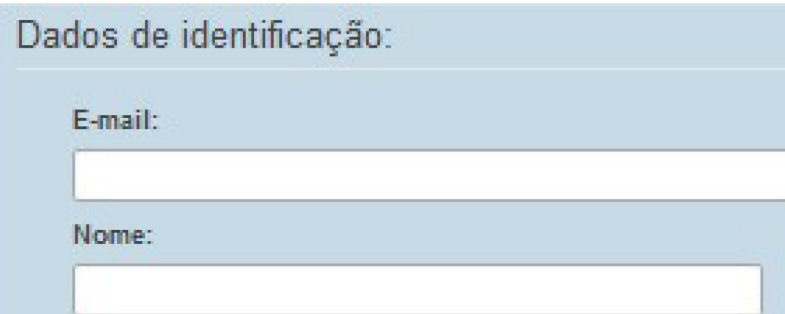

Matricula:

Dados de localização:

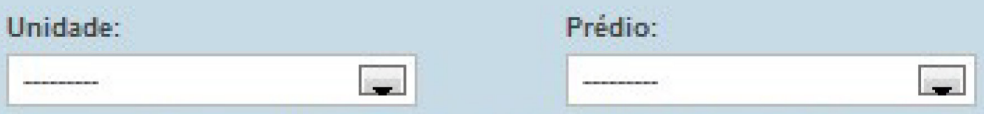

Caso seu prédio năo esteja relacionado na lista, selecione o mais próximo e especifique o seu no campo complemento.

Complemento:

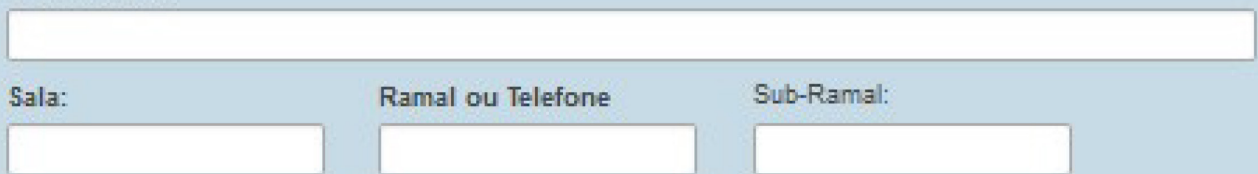

Dados do equipamento:

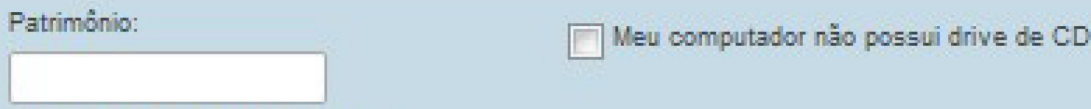

Breve descrição do problema:

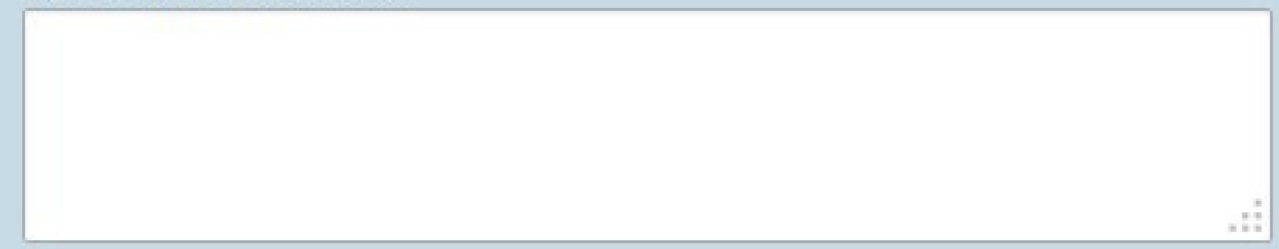

Enviar

Fonte: dos autores (2018).

A Figura 2 presenta um fluxo de atendimento dos chamados, onde cada chamado tem um início e um fim. O usuário realiza um chamado, o técnico avalia o mesmo e entra em contato com o usuário. Se o problema puder ser resolvido remotamente, o problema estará resolvido. Caso não seja possível, o técnico realiza atendimento local, para tentar resolver o problema. Caso não consiga resolver, então são procuradas alternativas possíveis. Sendo assim, o problema se encerra. 
Figura 2 - Fluxo de atividade de atendimentos realizados pela equipe de $\mathrm{TI}$

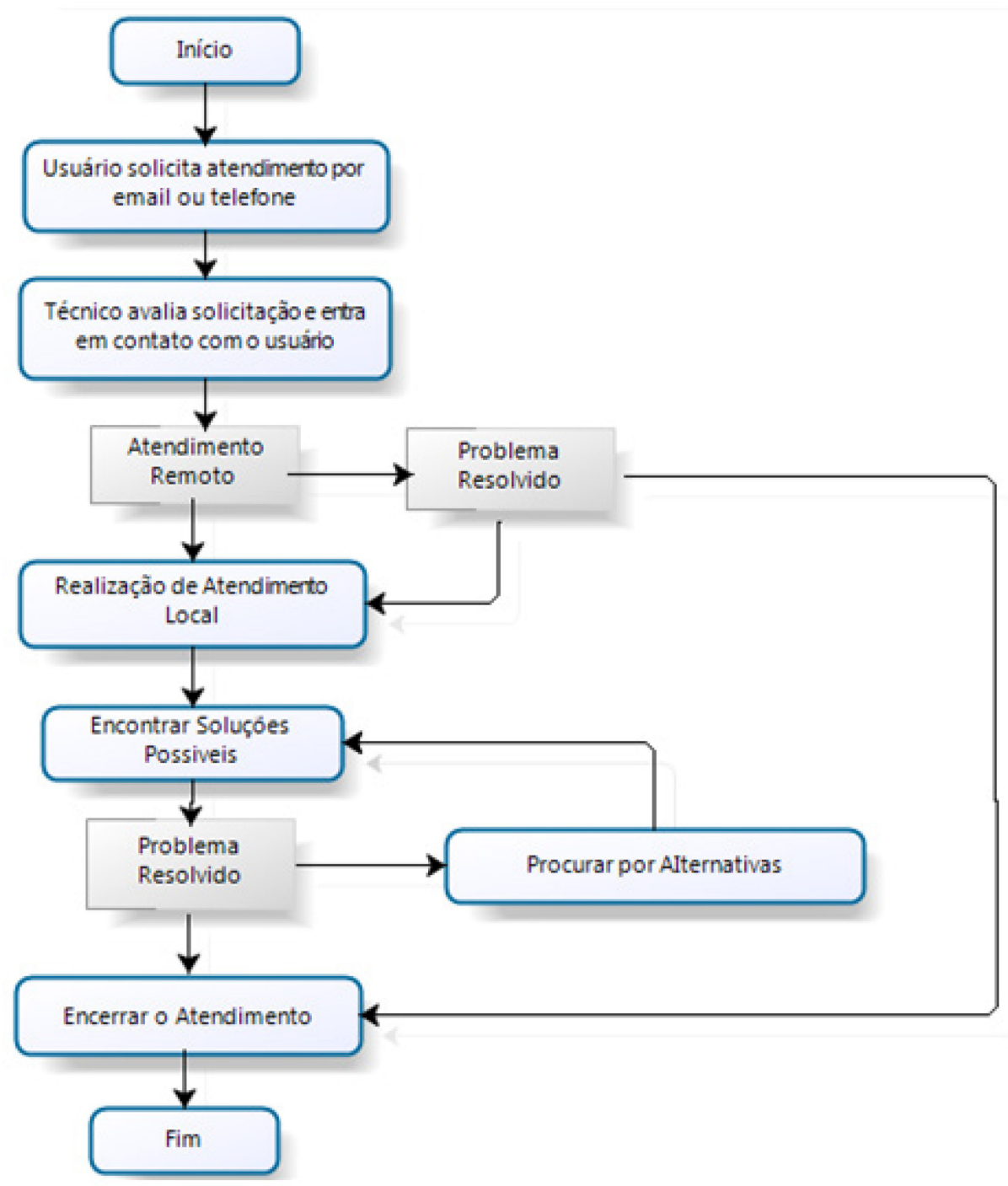

Fonte: dos autores (2018).

\subsection{Gestão de Incidentes}

No ITIL (ITIL, 2011), o Gerenciamento de Incidentes tem, como foco principal, reestabelecer serviço, minimizando o impacto negativo no negócio, uma solução de contorno ou reparo rápido fazendo com que o cliente volte a trabalhar. Além disso, garantir os melhores níveis de disponibilidade e de qualidade dos serviços, mantendo os acordos de nível de serviço, também é uma tarefa da gerência de incidentes.

Analisando os dados do Sistema de Chamados da UFSM/FW, observa-se que o principal motivo para abertura de chamados é relacionado às impressoras. Em seguida estão problemas relacionados à rede da universidade. Também é possível observar que existem serviços que nunca tiveram solicitação de chamados, tais como os referentes à manutenção de roteadores ou relacionados ao controle de ponto eletrônico dos servidores.

Também com base na análise dos dados do Sistema de Chamados, verifica-se que nos meses janeiro e fevereiro o número de chamados é menor. Cabe ressaltar que os meses destacados correspondem às férias letivas na UFSM. Dessa forma, os alunos não estão presentes no campus, por consequência o fluxo de pessoas, bem como a utilização dos equipamentos também diminui. Assim, os chamados são menores, devido a menor 
utilização de equipamentos. Analisando o índice de satisfação com relação à resolução dos chamados, foi possível observar que a resolução dos problemas ocorridos é muito satisfatória.

\subsection{Análise da Governança de TI aplicada na UFSM/FW}

Para analisar como a Governança de TI estava sendo aplicada na UFSM/FW foi elaborado um instrumento de pesquisa (questionário semiestruturado), que teve como objetivo principal o de colher informações e opiniões das pessoas que estão envolvidas no cotidiano da universidade (professores, técnicosadministrativos e alunos), buscando identificar a visão dos entrevistados sobre a infraestrutura tecnológica do mesmo, o conhecimento que possuem sobre a importância de se ter a equipe de TI em perfeitas condições de trabalho e o grau de satisfação que a comunidade acadêmica apresenta em relação à equipe e equipamentos disponíveis no campus. O instrumento utilizado foi baseado no Plano Diretor de TI da UFSM (MULLER, 2013).

O instrumento proposto foi subdividido entre os temas: Sistemas de Informação, Serviços Disponíveis, Infraestrutura, Equipe de TI, Conhecimento que a comunidade acadêmica tem em relação a tais contextos e, também, o grau de satisfação da mesma em relação a estes processos. Foram obtidas 59 respostas, sendo dessas 21 de alunos $(35,6 \%), 15$ de técnicos $(25,4 \%)$ e 23 de professores $(39 \%)$, como mostra o gráfico da Figura 3.

Figura 3 - Respondentes por Categoria

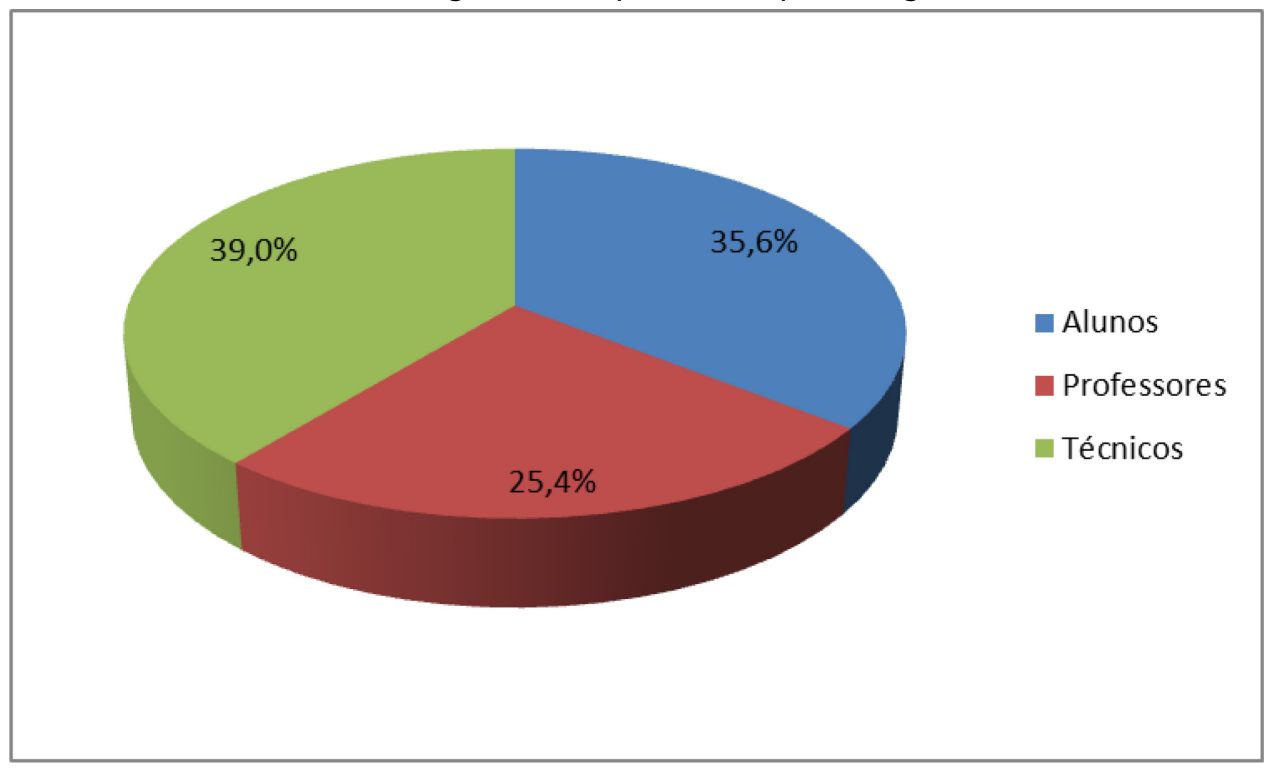

Fonte: dos autores (2018).

A primeira questão do instrumento: "Em se tratando de Sistemas de Informação: Os recursos de tecnologia de informação disponíveis são suficientes para atender aos objetivos da UFSM campus Frederico Westphalen?", a mesma foi dividida em 6 categorias: 1) Portais SIE-Web; 2) Página Web da UFSM; 3) Ferramentas de Comunicação; 4) Ferramentas de Apoio à Educação; 5) Ambiente Virtual de Aprendizagem Moodle; e 6) Outros Aplicativos e/ou Planilhas para Controle Interno.

Os resultados são: 1) Portais SIE-Web" (Portal do Professor, de Recursos Humanos, Produção Institucional, Portal do Aluno etc.), 4 pessoas responderam concordar totalmente com a questão $(6,8 \%)-$ indicando que os recursos são suficientes, 42 concordaram (71,2\%), 2 manifestaram-se indiferentes $(3,4 \%)$ e 11 discordaram (18,6\%).

Com relação à categoria 2) "Página Web da UFSM", 9 pessoas responderam concordar totalmente com a questão (15,3\%), 28 concordaram (47,5\%), 8 manifestaram-se indiferentes (13,6\%) e 14 discordaram $(23,7 \%)$. 
Na categoria 3) "Ferramentas de comunicação (páginas web, blogs, notícias, redes sociais etc.)", 8 pessoas responderam concordar totalmente com a questão (13,6\%), 31 concordaram (52,5\%), 8 manifestaramse indiferentes (13,6\%), 10 discordaram (16,9\%) e 2 discordaram totalmente $(3,4 \%)$.

Com relação às "Ferramentas de apoio à educação (apresentação de slides, vídeos, elaboração de texto etc.)", 7 pessoas responderam concordar totalmente com a questão (12,1\%), 26 concordaram (44,8\%), 10 manifestaram-se indiferentes (17,2\%), 12 discordaram $(20,7 \%)$ e 3 discordaram totalmente $(5,2 \%)$.

Para a categoria 5) "Moodle", 10 pessoas responderam concordar totalmente com a questão (16,9\%), 21 concordaram (35,6\%), 19 manifestaram-se indiferentes (32,2\%), 7 discordaram $(11,9 \%)$ e 2 discordaram totalmente $(3,4 \%)$.

Com relação à última categoria, "Outros aplicativos e/ou planilhas para controle interno", 1 pessoa respondeu concordar totalmente com a questão (1,7\%), 17 concordaram (28,8\%), 30 manifestaram-se indiferentes (50,8\%), 10 discordaram (16,9\%) e 1 discordou totalmente (1,7\%). Neste mesmo tópico foram realizadas várias sugestões de possíveis melhorias, entre elas o desenvolvimento de algum aplicativo que auxilie a fazer agendamentos no RU e um sistema para inscrição em eventos (que pudesse ser parametrizado para atender diferentes eventos da UFSM), além de um sistema que permitisse realizar uma das partes da avaliação institucional, que é a avaliação interna de cada curso junto aos discentes. A Figura 4 apresenta um gráfico com os percentuais de respostas da primeira questão.

Figura 4 - Percentuais de Respostas da 1a Questão

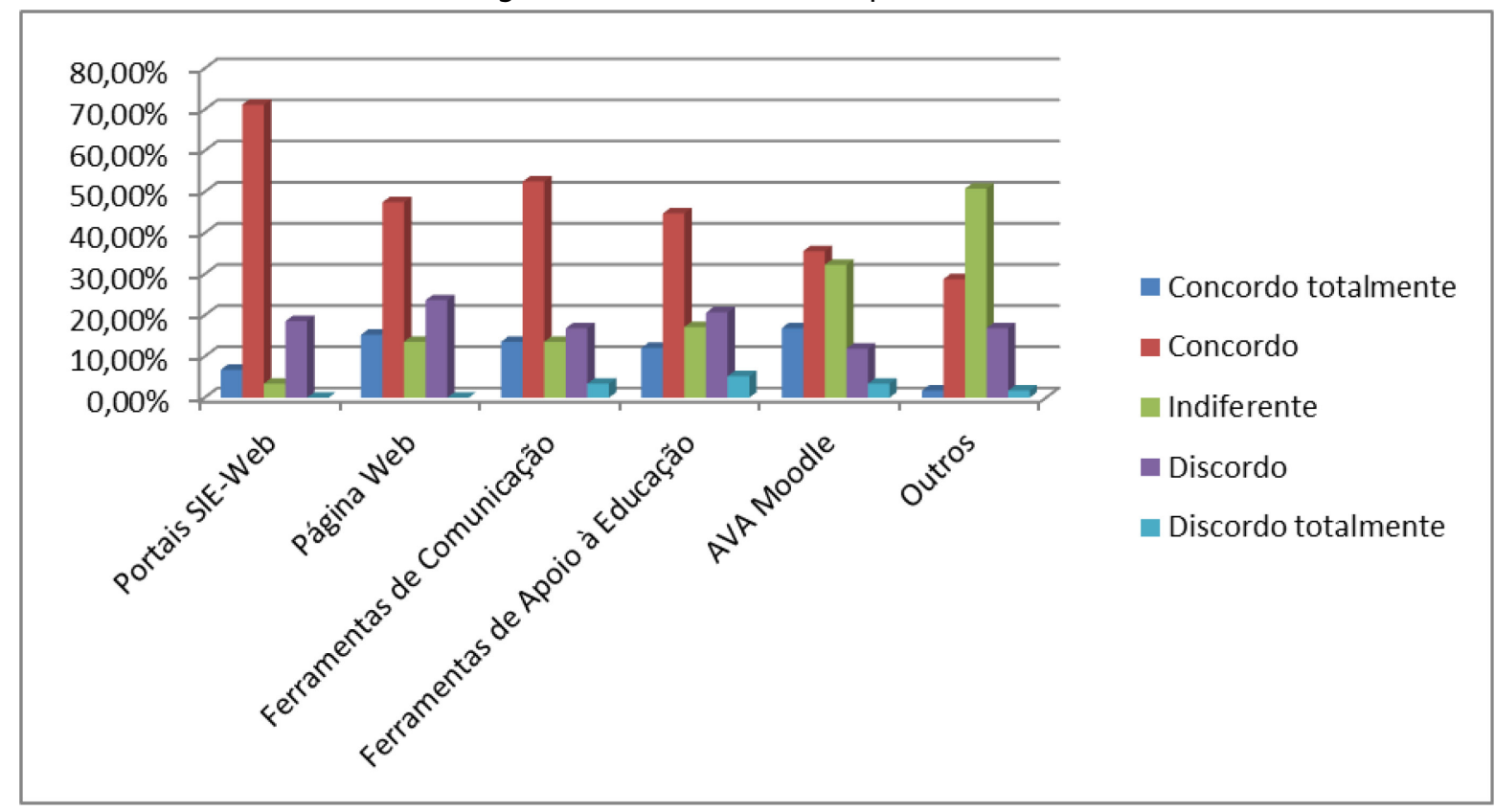

Fonte: dos autores (2018).

A segunda questão: “Em se tratando de serviços: Os recursos de Tecnologia de Informação disponíveis são suficientes para atender aos objetivos da UFSM campus Frederico Westphalen", também tinha diferentes categorias, sendo elas: 1) Suporte, 2) Capacitação e 3) Dúvidas e Orientações.

Com relação ao Suporte, 8 pessoas responderam concordar totalmente, destacando que os serviços são suficientes (13,6\%), 34 concordaram (57,6\%), 8 manifestaram-se indiferentes (13,6\%), 7 discordaram $(11,9 \%)$ e 2 discordaram totalmente (3,4\%). Envolvendo a alternativa de Capacitação, 6 pessoas responderam concordar totalmente com a questão (10,2\%), 26 concordaram (44,1\%), 12 manifestaram-se indiferentes (20,3\%), 14 discordaram (23,7\%) e 1 discordou totalmente (1,7\%). Com relação a "Dúvidas, orientações etc." 7 pessoas responderam concordar totalmente com a questão (12,1\%), 31 concordaram (53,4\%), 9 manifestaramse indiferentes (15,5\%) e 11 discordaram (19\%). Esta questão levanta a necessidade de melhorias, para assim poder se atingir de uma forma mais ampla todo o setor requerente de serviços. Cabe destacar que um dos 
participantes não respondeu à terceira categoria. A Figura 5 apresenta um gráfico com os percentuais de respostas da segunda questão.

Figura 5 - Percentuais de Respostas da 2a Questão

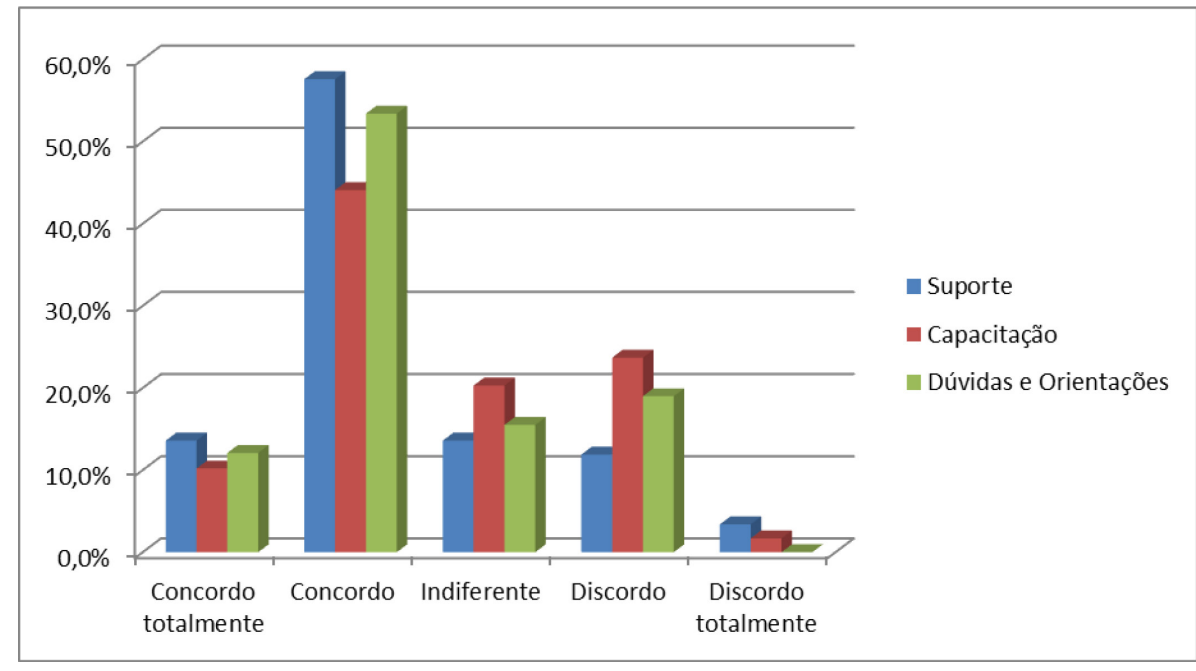

Fonte: dos autores (2018).

Com relação à terceira questão do instrumento: "Em se tratando de Infraestrutura: Os recursos de Tecnologia de Informação disponíveis são suficientes para atender os objetivos da UFSM campus Frederico Westphalen", a mesma foi dividida nas categorias 1) Equipamentos, 2) Redes e 3) Internet. Na categoria "Equipamentos", 2 pessoas responderam concordar totalmente com a questão (3,4\%), 21 concordaram (35,4\%), 2 manifestaram-se indiferentes (3,4\%), 27 discordaram (45,8\%) e 7 discordaram totalmente $(11,9 \%)$.

Com relação à categoria "Redes", 12 pessoas concordaram que os recursos disponíveis são suficientes $(20,3 \%), 12$ manifestaram-se indiferentes $(20,3 \%), 25$ discordaram $(42,4 \%)$ e 10 discordaram totalmente $(16,9 \%)$.

$\mathrm{Na}$ alternativa relacionada à "Internet", 10 pessoas concordaram que os recursos são suficientes $(16,9 \%), 5$ manifestaram-se indiferentes (8,5\%), 26 discordaram (44,1\%) e 18 discordaram totalmente $(30,5 \%)$.

Os resultados mostram que a comunidade acadêmica está à espera de melhorias, ou seja, há a necessidade de investimento na melhoria tanto de redes, acesso à Internet, bem como de equipamentos. A Figura 6 apresenta um gráfico com os percentuais de respostas da terceira questão.

Figura 6 - Percentuais de Respostas da 3a Questão

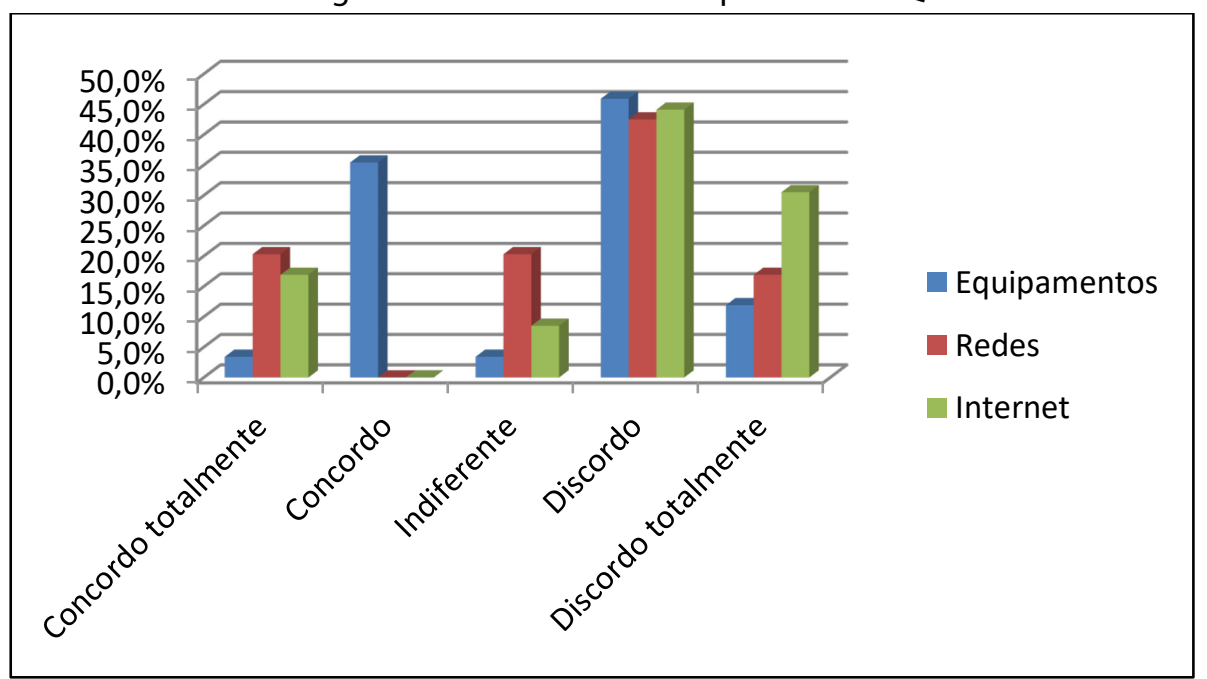

Fonte: dos autores (2018). 
Na questão: "Quanto à equipe de Tecnologia de Informação, comentar sobre a importância", foi abordada a atuação da equipe e sua importância para a UFSM/FW. As respostas foram descritivas. A comunidade acadêmica descreveu que "a equipe de Tl é de fundamental importância. Sem eles não tem como a Universidade caminhar, por exemplo, quando dá problema na Internet eles que tentam resolver ou entram em contato para resolverem, qualquer problema nos equipamentos são eles que são chamados, ou seja a universidade não anda sem essa equipe".

Também foi respondido que a equipe do Núcleo de Informática auxilia em muito nas atividades desempenhadas pelo Curso de Sistemas de Informação, ajudando a manter os laboratórios de informática em funcionamento (hardware e software), além do apoio aos eventos, tais como a JASI (Jornada Acadêmica de Sistemas de Informação) e o Encontro do GDG MAU (Grupo de Desenvolvedores Google do Médio Alto Uruguai), entre outros.

Na próxima pergunta: "Existem atividades importantes que a UFSM campus Frederico Westphalen está deixando de realizar devido à falta ou precariedade dos recursos de Tecnologia de Informação disponíveis", 57 pessoas responderam, sendo que 22 entrevistados (38,6\%) disseram sim, a universidade está deixando de realizar atividades importantes, $7(12,3 \%)$ responderam não e $28(49,1 \%)$ afirmaram não ter conhecimento sobre o assunto. Os resultados são apresentados, graficamente, na Figura 7.

Figura 7 - Desenvolvimento de Atividades

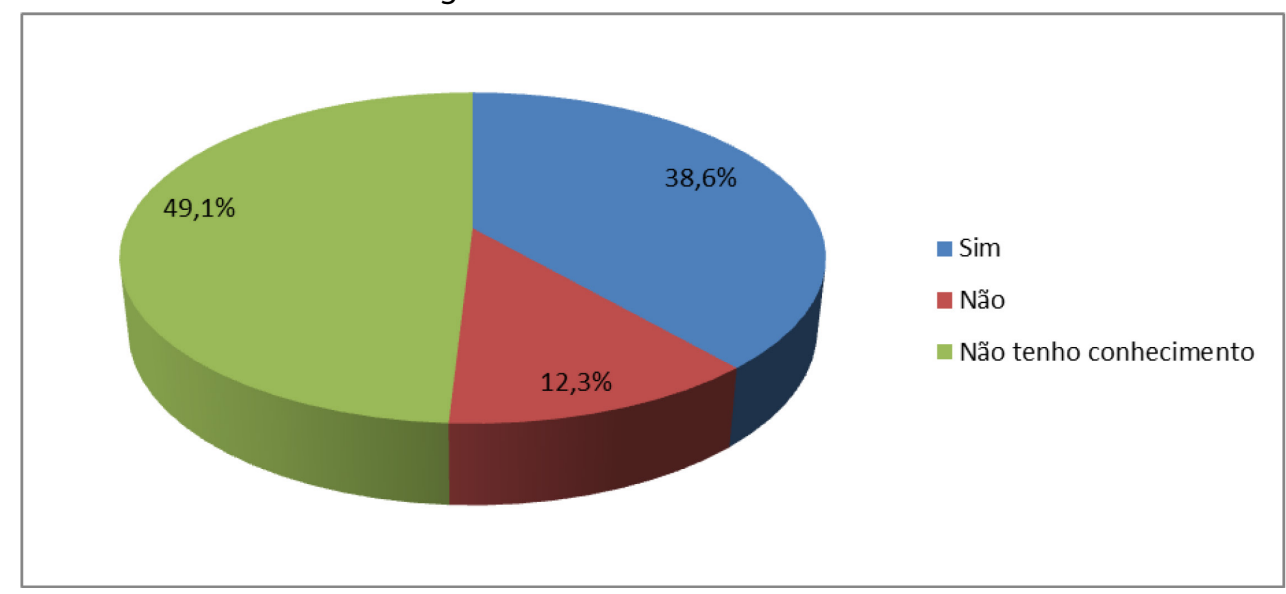

Fonte: dos autores (2018).

Em seguida questionou-se quais seriam essas atividades obtendo como resposta: melhorias no ensino, facilidade de comunicação, relações institucionais e extrainstitucionais, videoconferências, transmissões, eventos, agilidade nos processos e melhorias no acesso à Internet.

Na sequência a esta questão: “Em sua opinião, quais são as três principais necessidades de TI da UFSM campus Frederico Westphalen?". Entre outras respostas, os entrevistados destacaram: melhoria da Internet; capacitação sobre o SIE (Sistema de Informações Educacionais), criação de planilhas/sistemas para facilitar o acompanhamento e a avaliação dos serviços prestados e da população atendida e melhoria na telefonia.

Na última questão: "De uma forma geral, o grau de satisfação que tenho em relação à UFSM campus Frederico Westphalen, com os recursos de TI disponibilizados, é condizente com minhas necessidades." Apenas 1 pessoa respondeu concordar totalmente com a questão (1,7\%), 36 concordaram (61\%), 6 manifestaram-se indiferentes (10,2\%), 14 discordaram (23,7\%) e 2 discordaram totalmente (3,4\%). A Figura 8 mostra os resultados da questão de satisfação com os recursos de TI disponíveis na UFSM/FW, para a comunidade acadêmica. 
Figura 8 - Grau de Satisfação da Comunidade Acadêmica

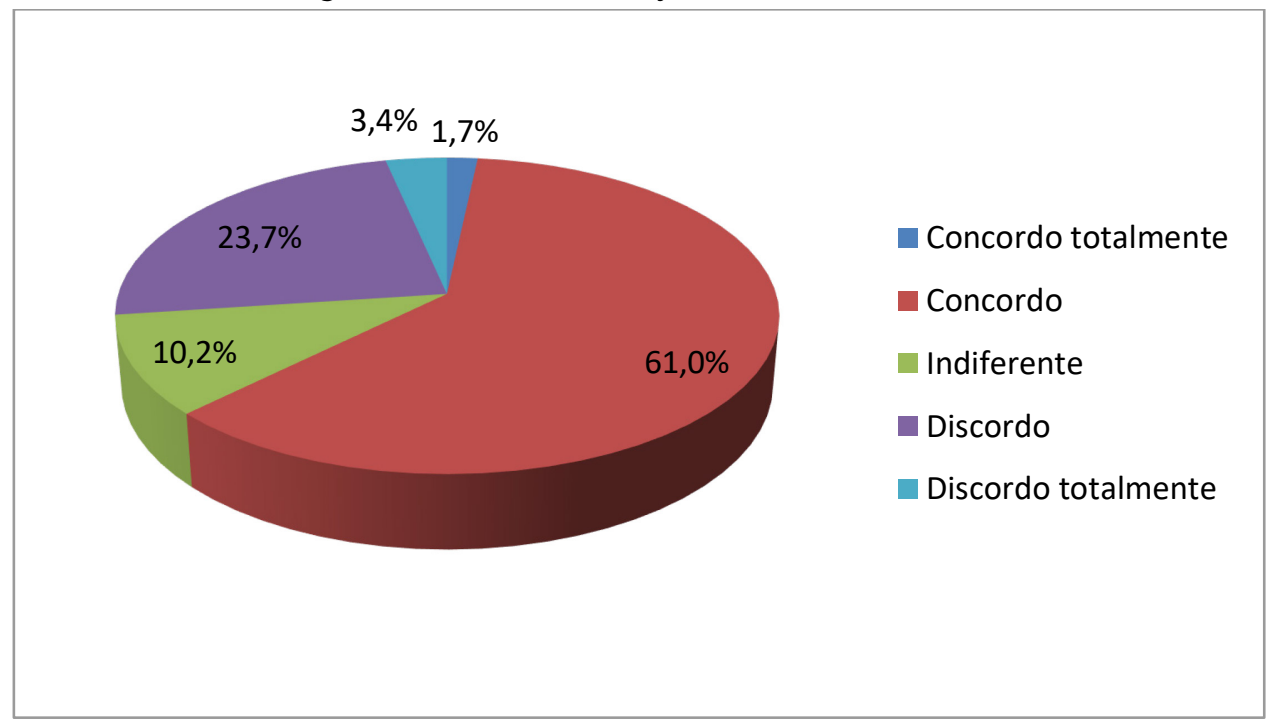

Fonte: dos autores (2018).

No final do instrumento havia um espaço para comentários e sugestões. Os respondentes indicaram a necessidade de melhorias nos sistemas de Internet, telefonia, além da realização de treinamentos para que professores de distintas áreas possam aplicar TI nas práticas de ensino e pesquisa. Também destacaram a urgência em providenciar espaço para aulas a distância (considerando o isolamento físico do campus em relação ao campus sede e outros campi da universidade). Também foram solicitadas melhorias de equipamentos para incentivar a fixação de professores em campus isolado.

\subsection{Mapeamento de serviços usando ITIL}

A ITIL (ITIL, 2011) diz que o mapeamento de serviço é estabelecer como o serviço vai proceder, como vai ser controlado e desenhado. Para isso é necessária uma esquematização, utilizando Portfólio de Serviços e Catálogo de Serviços. A Figura 9 representa um modelo de Governança de TI, com seus principais frameworks de governança: COBIT, ITIL e ISO/IEC38500. A Figura 9 apresenta um esboço da UFSM que, além do campus sede, localizado em Santa Maria - RS, ainda possui 4 campi distribuídos no interior do Estado do RS (Cachoeira do Sul, Frederico Westphalen, Palmeira das Missões e Silveira Martins).

Figura 9 - Demonstrativo de estudo de Governança de TI em relação à UFSM campus de Frederico Westphalen

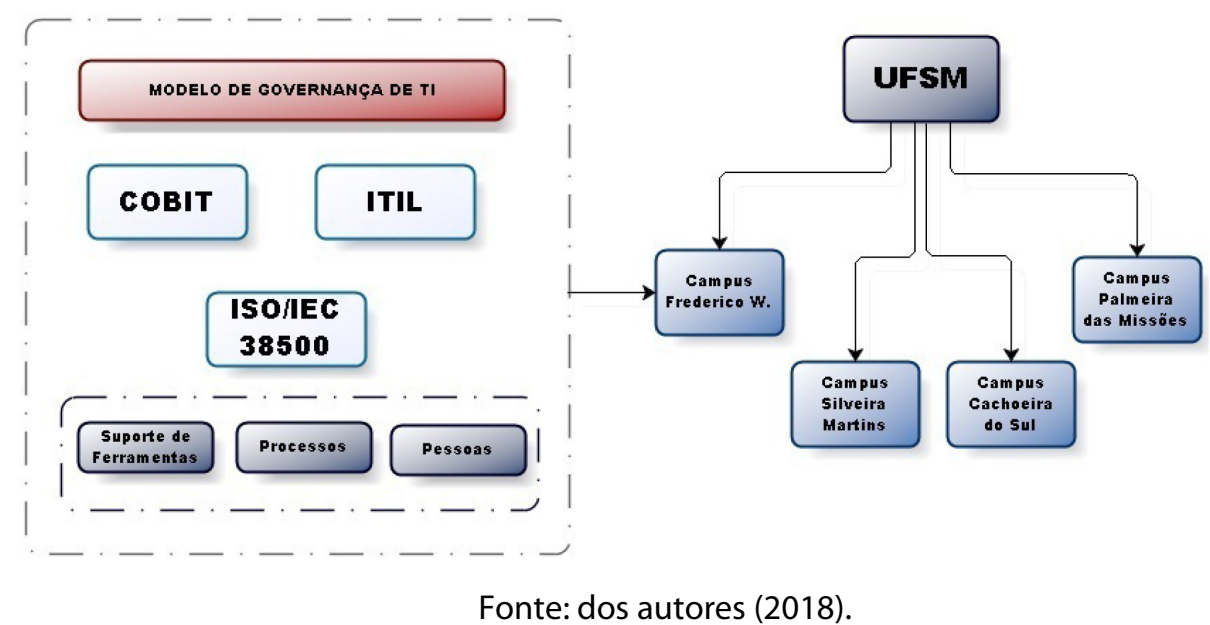


A Figura 10 apresenta um plano de implantação de Governança de TI na UFSM/FW, delimitando ações que direcionariam à implantação da mesma. O plano está dividido em oito passos, que destacam as ações até chegar à aprovação do programa. Na sequência, a elaboração de planos de gerência de mudanças e aprimoramento da implantação, implantando os projetos, monitorando e avaliando os mesmos para, dessa forma, comunicar os resultados.

Figura 10 - Projeto de Roteiro de Implantação no Campus de FW

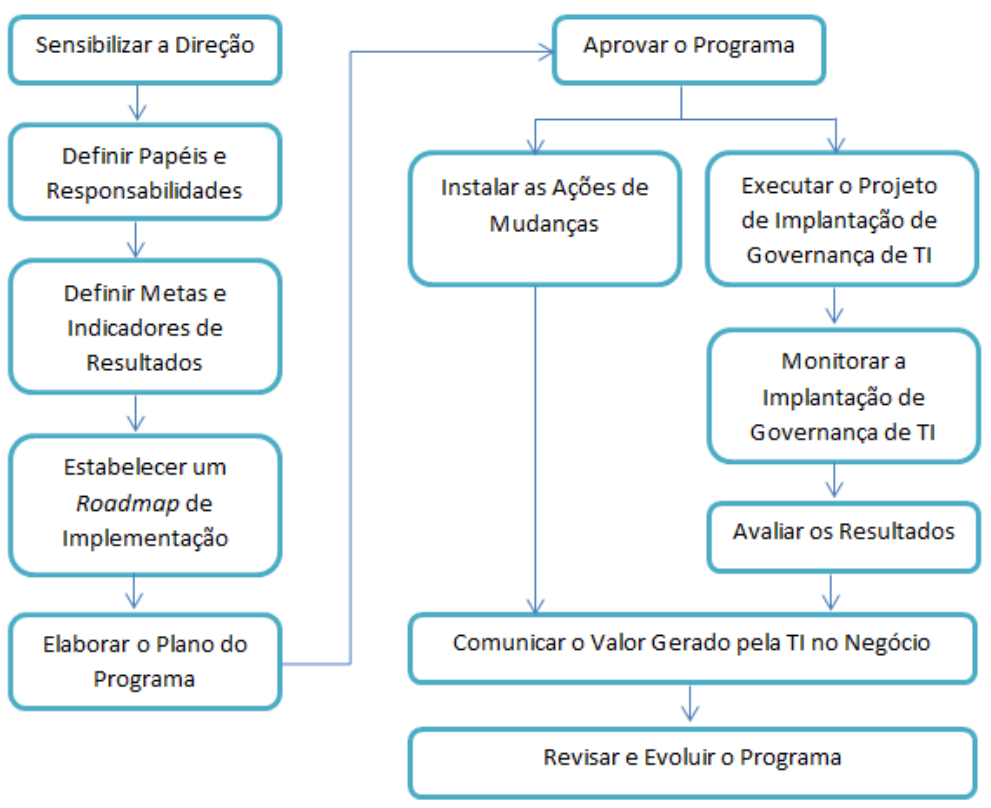

Fonte: dos autores (2018).

De acordo com a Figura 10 têm-se que:

- Sensibilizar a direção: ter o apoio da direção para, dessa forma, conseguir angariar recursos para desenvolver as atividades necessárias à implantação da Governança de TI no campus. Para fundamentar essa ação podem ser utilizados vários instrumentos, entre eles palestras, visitas a outras organizações que já fazem uso de Governança de TI, mostrando possíveis resultados que a mesma pode gerar;

- Definir papéis e definir responsabilidades: definir quem realizará cada atividade e a responsabilidade que terá em relação a tal atividade para, dessa forma, atingir o objetivo final (alta administração, área de auditoria, compliance e riscos, desenvolvimento, suporte, infraestrutura tecnológica, segurança da informação);

- Estabelecer metas e indicador final: traçar as ações, determinar o que se quer ter ao final dessas ações e de que forma se pretende chegar ao final dessas ações;

- Estabelecer um roadmap de implantação: estabelecendo ações de curto, médio e longo prazo, identificando as ações de maior prioridade. Identificar o que precisa ser feito, definir a sequência das atividades a serem implantadas, identificando os benefícios que poderão ser alcançados;

- Elaborar o plano do programa: definir quais projetos farão parte do programa e definir o escopo. Após elaborar o roadmap, delimitar quais projetos farão parte do programa, delimitando escopo, estrutura e ações de TI, sequência de implantação dos processos, em uma linha de tempo pré-estabelecida;

- Aprovar o programa: após ter o plano pronto, realizar a aprovação do mesmo para dar início à implantação da Governança de Tl;

- Implantar as ações de mudança: colocar em prática o que foi planejado; 
- Executar os projetos de implantação de Governança de TI: executar o que anteriormente foi planejado de forma organizada;

- Monitorar a implantação: realizar o monitoramento, para prever necessidades de mudanças ou realizar alterações no plano;

- Avaliar os resultados: avaliar os resultados, para definir os próximos passos;

- Comunicar os resultados alcançados: tomar decisões em conjunto é a melhor forma de se ter sucesso;

- Revisar e evoluir o programa: adaptar o plano para, dessa forma, ter sucesso nos passos futuros.

\section{PROPOSTA DE GOVERNANÇA DE TI}

A Governança de TI requer das organizações decisão, compromisso, priorização e alocação de recursos referentes às responsabilidades pelas decisões relativas à TI. Trata-se dos envolvidos que irão tomar as decisões. Sendo assim, tomar as decisões de forma responsável exige estratégias e alocação adequada dos recursos disponíveis na organização.

\subsection{ISO/IEC 38500 e seus Princípios}

Como fundamentação para o estudo de caso em questão foi utilizada a norma ISO/IEC38500 (ISO, 2008). Esta norma oferece princípios para orientar os dirigentes da organização sobre o uso eficaz, eficiente e aceitável da TI. Entre os princípios da norma ISO foram utilizados (ISO, 2008):

- Responsabilidade: os indivíduos e grupos, dentro da organização, compreendem e aceitam suas responsabilidades em relação à TI, tendo autonomia, concluindo que pessoas são os principais ativos de qualquer organização O princípio Responsabilidade da norma ISO/IEC38500 fundamenta a visão das organizações e as exigências que são feitas em relação às pessoas que nela são inseridas;

- Estratégia: levam em conta as capacidades atuais e futuras de TI. Os planos estratégicos para $\mathrm{TI}$ satisfazem as necessidades atuais e contínuas da estratégia de negócio da organização, envolvendo um posicionamento, pesquisa de produto, praça, preço e possíveis promoções A responsabilidade é muito importante dentro da organização, é por meio dela que cada função é exercida e executada. Os diretores devem acompanhar o desenvolvimento das atividades. Os dois princípios citados anteriormente são direcionadores para a tomada de decisão, tentando obter vantagens competitivas, alinhando a TI com o negócio da organização. Assim como a Responsabilidade, a Estratégia também segue o modelo onde avaliar, direcionar e monitorar assume um papel importante. Analisando a ferramenta estudada - CITSMART, a responsabilidade de determinadas atividades pode ser direcionada para grupos de trabalhos pré-definidos. Assim, o sistema CITSMART direcionará essa atividade para tal grupo, definido como grupo executor. Também é possível delimitar estratégias de trabalho usando o framework ITIL por meio da ferramenta CITSMART, dessa forma tornando as ações controladas, sendo possível gerar relatórios para análise. Para realizar essas atividades existe a possibilidade de uso de catálogos de serviços ITIL e portfólios de serviços, entre outras ferramentas de ajuda que o ITIL disponibiliza.

\subsection{Portfólio de Serviços}

Portfólio de Serviços é um conjunto completo de serviços que serão entregues. São agrupados por tamanho, disciplina e valor estratégico, ou seja, o portfólio engloba todos os serviços entregues pela organização, ou pela área de Tl, também os que estão aposentados ou obsoletos por, de certa forma, ainda serem úteis para a organização e, por último, os serviços propostos ou em desenvolvimento. A gestão de portfólio tem, como objetivo, o de gerenciar os serviços durante todo o ciclo de vida do mesmo. O gerenciamento do portfólio serve para organizar investimentos a serem feitos na organização (ITIL, 2011). 
Para Cestari Filho (2011), no Portfólio de Serviços devem estar postos todos os serviços existentes no Catálogo de Serviços da organização. O gerenciamento de serviços inclui: definir, analisar, aprovar e controlar:

- Definir - levantar os dados existentes no Portfólio, verificando o que melhorar para agregar valor;

- Analisar - analisar as demandas de serviços para identificar o que agrega valor à organização;

- Aprovar - aprovar o portfólio proposto, autorizando recursos e serviços futuros; e

- Controlar - comunicar decisões, alocar recursos para o início de atividades, renovar o portfólio.

\subsection{Catálogo de Serviços}

A ITIL (ITIL, 2011) define catálogo de serviços como parte do Portfólio disponível para um cliente. São os serviços ativos na visão do cliente em específico. Este cliente será representado por uma organização com a qual mantém contrato. Na gestão do catálogo, o objetivo é que todas as informações dos serviços ativos estejam claramente disponíveis e especificadas para os clientes. O gestor do processo tem um papel tático na prestação dos serviços de TI.

O Catálogo de Serviços deve ser entendido como a principal ferramenta de comunicação entre a TI e o negócio, garantindo que os processos de demanda e oferta de serviços sejam executados de forma eficaz. Um bom Catálogo de Serviços é o primeiro passo para uma boa Gestão de Serviços de TI.

Ao analisar a pesquisa realizada, com base na ferramenta Help Deskusada no setor de TI da UFSM/FW, identificaram-se os tipos de serviços prestados pelos membros do setor e quais eram suportados pela ferramenta de Help Desk. Constatou-se que a ferramenta atende apenas um tipo de serviço, sendo ele a Abertura de Chamados e que, no momento, é usada para controle interno do setor de TI, ou seja, essa ferramenta não é institucionalizada e a população acadêmica não possui acesso à mesma.

Na ferramenta Help Desk utilizada pelo setor de TI são armazenados dados de diversas formas de atendimentos que são solicitados, entre eles a instalação de sistemas operacionais, manutenção de programas instalados para os usuários, suporte de redes, enfim, necessidades enfrentadas pelos usuários em relação à hardware e software em geral, identificando como cliente toda a comunidade acadêmica (professores, técnico-administrativos, alunos e demais funcionários da universidade).

O Quadro 1 apresenta a descrição do serviço "Suporte de Redes", onde é colocado o nome de serviço realizado, o status em que ele se encontra, como está sendo realizado e quem são os clientes do serviço prestado (nesse caso é toda a comunidade acadêmica). $O$ atendimento de Suporte de Redes é realizado pelos técnicos de TI da UFSM/FW e sofre dependência, muitas vezes, da telefonia, pois é por meio do telefone que são realizados os chamados.

Quadro 1 - Análise de Portfólio: Suporte de Redes

\begin{tabular}{|l|l|}
\hline \multicolumn{1}{|c|}{ Nome do Serviço } & \multicolumn{1}{c|}{ Suporte de Redes } \\
\hline Status atual do serviço & $\begin{array}{l}\text { O serviço é realizado pela equipe de TI da UFSM/FW, composta por 3 } \\
\text { colaboradores efetivos e 2 bolsistas. }\end{array}$ \\
\hline Tipo de Serviço & $\begin{array}{l}\text { Suporte de redes, atendimento na manutenção e correção de erros ocorridos } \\
\text { na rede do campus. }\end{array}$ \\
\hline Clientes & $\begin{array}{l}\text { Toda a comunidade acadêmica: professores, servidores técnicos, } \\
\text { terceirizados, alunos. }\end{array}$ \\
\hline Descrição do Serviço & $\begin{array}{l}\text { O serviço é realizado sempre que solicitado, sendo realizada a manutenção } \\
\text { das redes existentes, para corrigir eventuais problemas. }\end{array}$ \\
\hline Justificativa & $\begin{array}{l}\text { Conseguir atender os clientes, para que as dificuldades enfrentadas sejam } \\
\text { solucionadas, os dados encontrados geram feedback. }\end{array}$ \\
\hline Resultados Desejados & $\begin{array}{l}\text { Satisfação do usuário, em relação à rede, para que os mesmos possam } \\
\text { realizar suas atividades. }\end{array}$ \\
\hline Dependência & $\begin{array}{l}\text { O atendimento sofre dependência da telefonia, já que os chamados são } \\
\text { feitos por meio do telefone. }\end{array}$ \\
\hline $\begin{array}{l}\text { Mudanças planejadas para } \\
\text { o Serviço }\end{array}$ & \begin{tabular}{l} 
A falta de mão de obra não possibilita a realização de melhorias. \\
\hline
\end{tabular}
\end{tabular}




\begin{tabular}{|l|l|}
\hline $\begin{array}{l}\text { Referências a Planos } \\
\text { Pertinentes }\end{array}$ & Necessidade de aperfeiçoamento, para efetuar melhorias. \\
\hline Business Case & Riscos decorrentes da dependência. \\
\hline
\end{tabular}
Fonte: dos autores (2018).

O Quadro 2 apresenta a descrição do serviço "Suporte e Instalação de Software", onde consta o nome de serviço realizado, o status em que ele se encontra, como está sendo realizado e quem são os clientes do serviço prestado. O atendimento de Suporte de Softwares é realizado pelos técnicos de TI da UFSM/FW e sofre dependência muitas vezes, da telefonia, pois é por meio dela que são realizados os chamados. Também apresenta uma necessidade de aperfeiçoamento de mão de obra, pois a equipe é pequena e não consegue tempo para tal atividade.

Quadro 2 - Análise de Portfólio: Suporte e Instalação de Software

\begin{tabular}{|c|c|}
\hline Nome do Serviço & Suporte e Instalação de Software \\
\hline Status atual do serviço & $\begin{array}{l}\text { O serviço é realizado pela equipe de TI da UFSM/FW, composta por } 3 \\
\text { colaboradores efetivos e } 2 \text { bolsistas. }\end{array}$ \\
\hline Tipo de Serviço & $\begin{array}{l}\text { Suporte à software, orientação de uso de programas, por exemplo. } \\
\text { Instalação de softwares necessários para atendimento de necessidades. }\end{array}$ \\
\hline Clientes & $\begin{array}{l}\text { Toda a comunidade acadêmica: professores, servidores técnicos, } \\
\text { terceirizados, alunos. }\end{array}$ \\
\hline Descrição do Serviço & $\begin{array}{l}\text { Manutenção de software, instalação de software, treinamento com os } \\
\text { usuários para utilizar o software requisitado. }\end{array}$ \\
\hline Justificativa & $\begin{array}{l}\text { Conseguir atender os clientes, para que as dificuldades sejam } \\
\text { solucionadas. Os dados encontrados geram feedback, permitindo o } \\
\text { controle do que foi realizado. }\end{array}$ \\
\hline Resultados Desejados & Satisfação do usuário, em relação ao software. \\
\hline Dependência & $\begin{array}{l}\text { O atendimento sofre dependência da telefonia, já que os chamados são } \\
\text { feitos por meio do telefone. }\end{array}$ \\
\hline $\begin{array}{l}\text { Mudanças planejadas para o } \\
\text { Serviço }\end{array}$ & A falta de mão de obra não possibilita a realização de melhorias. \\
\hline $\begin{array}{l}\text { Referências a Planos } \\
\text { Pertinentes }\end{array}$ & Necessidade de aperfeiçoamento, para efetuar melhorias. \\
\hline Business Case & Riscos decorrentes da dependência. \\
\hline
\end{tabular}

Fonte: dos autores (2018).

O Quadro 3 apresenta a descrição do serviço "Suporte a Hardware", onde consta o nome de serviço realizado, o status em que ele se encontra, como está sendo realizado e quem são os clientes do serviço prestado. O atendimento de Suporte a Hardware é realizado pelos técnicos de TI da UFSM/FW e sofre dependência, muitas vezes, da telefonia, pois é por meio dela que são realizados os chamados. A equipe desloca se para o atendimento no local do problema. Por ser uma equipe pequena, torna a rotina sobrecarregada.

Quadro 3 - Análise de Portfólio: Suporte a Hardware

\begin{tabular}{|l|l|}
\hline Nome do Serviço & \multicolumn{1}{|c|}{ Suporte a Hardware } \\
\hline Status atual do serviço & $\begin{array}{l}\text { O serviço é realizado pela equipe de TI da UFSM/FW, composta por } 3 \\
\text { colaboradores efetivos e 2 bolsistas. }\end{array}$ \\
\hline Tipo de Serviço & $\begin{array}{l}\text { Suporte a hardware, atendimento a eventuais problemas que ocorram nas } \\
\text { máquinas da universidade. }\end{array}$ \\
\hline Clientes & $\begin{array}{l}\text { Toda a comunidade acadêmica: professores, servidores técnicos, } \\
\text { terceirizados, alunos. }\end{array}$ \\
\hline Descrição do Serviço & $\begin{array}{l}\text { O serviço é realizado sempre que solicitado, sendo realizada a manutenção } \\
\text { de hardware, onde são corrigidos eventuais problemas. }\end{array}$ \\
\hline Justificativa & $\begin{array}{l}\text { Atender os clientes, para que as dificuldades sejam solucionadas. Os dados } \\
\text { encontrados geram feedback, permitindo o controle do que foi realizado. }\end{array}$ \\
\hline
\end{tabular}




\begin{tabular}{|c|l|}
\hline Resultados Desejados & $\begin{array}{l}\text { Satisfação do usuário, em relação ao hardware, para que possa realizar suas } \\
\text { atividades em perfeitas condições. }\end{array}$ \\
\hline Dependência & $\begin{array}{l}\text { O atendimento sofre dependência da telefonia, já que os chamados são } \\
\text { feitos por meio do telefone. }\end{array}$ \\
\hline $\begin{array}{c}\text { Mudanças planejadas } \\
\text { para o Serviço }\end{array}$ & A falta de mão de obra não possibilita a realização de melhorias. \\
\hline $\begin{array}{c}\text { Referências a Planos } \\
\text { Pertinentes }\end{array}$ & Necessidade de aperfeiçoamento, para efetuar melhorias. \\
\hline Business Case & Riscos decorrentes da dependência. \\
\hline
\end{tabular}

Fonte: dos autores (2018).

O Quadro 4 apresenta a descrição do serviço "Atendimento a Terceiros", onde consta o nome de serviço realizado, o status em que ele se encontra, como está sendo realizado e quem são os clientes do serviço prestado. Este serviço está relacionado com o auxílio às empresas terceirizadas que prestam serviços na universidade.

Quadro 4 - Análise de Portfólio: Atendimento a Terceiros

\begin{tabular}{|c|l|}
\hline Nome do Serviço & \multicolumn{1}{c|}{ Atendimento a Terceiros } \\
\hline Status atual do serviço & $\begin{array}{l}\text { O serviço é realizado pela equipe de TI da UFSM/FW, composta por 3 } \\
\text { colaboradores efetivos e 2 bolsistas. }\end{array}$ \\
\hline Tipo de Serviço & $\begin{array}{l}\text { Suporte ao atendimento a terceiros, em eventuais problemas que } \\
\text { ocorram nas atividades realizadas pelos terceirizados. }\end{array}$ \\
\hline Clientes & Terceirizados. \\
\hline Descrição do Serviço & $\begin{array}{l}\text { O serviço é realizado sempre que solicitado, sendo prestadas } \\
\text { informações para que sejam corrigidos eventuais problemas. }\end{array}$ \\
\hline Justificativa & $\begin{array}{l}\text { Atender os clientes, para que as dificuldades sejam solucionadas. Os } \\
\text { dados encontrados geram feedback, permitindo o controle do que foi } \\
\text { realizado. }\end{array}$ \\
\hline Resultados Desejados & Satisfação do usuário, em relação aos recursos de TI. \\
\hline Dependência & $\begin{array}{l}\text { O atendimento sofre dependência da telefonia, já que os chamados são } \\
\text { feitos por meio do telefone. }\end{array}$ \\
\hline $\begin{array}{l}\text { Mudanças planejadas para } \\
\text { o Serviço }\end{array}$ & A falta de mão de obra não possibilita a realização de melhorias. \\
\hline $\begin{array}{c}\text { Referências a Planos } \\
\text { Pertinentes }\end{array}$ & Necessidade de aperfeiçoamento, para efetuar melhorias. \\
\hline Business Case & Riscos decorrentes da dependência. \\
\hline
\end{tabular}

\section{CONCLUSÕES}

A partir deste estudo de caso foi possível concluir que Governança de Tl é uma ferramenta muito importante para que as organizações consigam manter-se em pleno funcionamento. Para isso existem frameworks para auxiliar nessa estruturação. Entre eles, os mais usados são: COBIT, ITIL e ISO/IEC38500. O embasamento teórico direcionou o estudo e, dessa forma, fez-se compreender que Governança de TI está em pleno desenvolvimento e sua importância é cada vez mais visível. Quando observada a utilização de Governança de TI na UFSM/FW, viu-se que a mesma é muito pouco utilizada.

Com o avanço da tecnologia e a aceleração cada vez maior da mesma, é importante o acompanhamento de Governança de TI em qualquer organização, seja ela pública ou privada de qualquer tamanho, já que a mesma dá suporte à tomada de decisões. Uma característica importante é que tudo que existir de controle na instituição pode ser aproveitado, não é necessário que seja começado do zero para existir Governança de TI. Pode-se partir das ferramentas existentes para, daí em diante, incrementá-las e criar planos de implementação. As organizações precisam ser controladas e, para isso, as mesmas precisam ser 
gerenciadas. Sendo assim, governança e gerência devem caminhar juntas, para que a organização possa atingir seus objetivos.

Ao estudar Governança de TI verificam-se diversas dificuldades para sua implantação. Entre elas está a necessidade de investimentos, tanto em recursos financeiros quanto em recursos humanos. Há a necessidade de pessoas treinadas e com tempo dedicado nesse processo, para dessa forma alinhá-la ao negócio. Uma alternativa relevante na questão é o uso de ferramentas livres disponíveis. Neste trabalho foi estudada a ferramenta CITSMART, que possibilita a cobertura de todas as áreas da UFSM/FW, sendo que a mesma disponibiliza serviços bem completos. O maior entrave encontra-se no treinamento das pessoas, já que o uso da ferramenta demanda mão de obra treinada.

Pelo fato da Governança de TI ser um assunto tão em alta na atualidade e ser um assunto que cada vez mais discutido pelas organizações, foi realizado o estudo aqui apresentado na UFSM/FW, por meio da análise da ferramenta de Help Desk utilizada. Verificou-se que a mesma não é institucionalizada, sendo usada apenas para controle interno do setor. Além disso, foi realizado um levantamento de portfólio de serviços da mesma, verificando-se que a ferramenta suporta apenas um serviço, que é a abertura de chamados. Por meio da ferramenta são cadastradas as atividades realizadas e, posteriormente, gerados relatórios.

Após o estudo da ferramenta de Help Desk utilizada na UFSM/FW, da análise dos resultados do questionário aplicado com a comunidade acadêmica e da proposta de aplicação da ferramenta CITSMART, é possível traçar os passos futuros para implantação da Governança de TI no campus. A análise de novas ferramentas possibilita aumentar o conhecimento e, assim, mostrar o quanto a Governança de TI é importante em uma organização. A coleta de novos dados e a institucionalização da ferramenta de Help Desk, que até momento é utilizada somente para controle interno do setor de TI da universidade, poderia ser um começo para o alinhamento de TI com as demais áreas da universidade (CITSMART, 2018).

\section{REFERÊNCIAS}

BALDIN, F.; BALDIN, S. Revolução Invisível: Uma nova forma de Gestão em Serviço. São Paulo: Biblioteca 24 horas, 2011.

CESTARI FILHO, F. ITIL V3 Fundamentos. Rio de Janeiro: Escola Superior de Redes RNP, 2011.

CITSMART. Citsmart: Intelligent governance. [2018]. Disponível em: http://www.citsmart.com.br/software/. Acesso em: 1 mar. 2018.

FERNANDES, Abreu V. Implantando a Governança de TI: da estratégia à gestão dos processos e serviços. Rio de Janeiro: Brasport, 2012.

ISACA. Cobit 5: Enabling process. [2012]. Disponível em: http://www.isaca.org. Acesso em: 25 mar. 2018.

ISO. ISO/IEC38500. International Standard. Corporate of Information Technology. Suíça: Universidad de Cadiz, 2008.

ITIL. ITIL Foundation. [2011]. Disponível em: http://www.mundoitil.com.br. Acesso em: 01 mar. 2018.

MANCINI, M.; ROSINI, A. O Cobit como modelo de Governança de TI aplicado em uma instituição financeira do Brasil. In: WORSKHOP DE PÓS-GRADUAÇÃO E PESQUISA DO CENTRO PAULA SOUZA, 8., 2013, São Paulo. Anais [...]. São Paulo: Universidade Presbiteriana Mackenzie, 2013.

MASSON, E.; PEREIRA, J. N.; SOUZA NETO, J. A governança de TI autônoma na administração pública federal. In:SIMPÓSIO DE EXCELÊNCIA EM GESTÃO E TECNOLOGIA, 11., 2014, Resende, RJ . Anais [...]. Resende, RJ: AEBD, 2014. Disponível em: https://www.aedb.br/seget/arquivos/artigos14/982061.pdf. Acesso em: 1 out. 2017. 
MORAIS, E. S. Benefícios identificados com a implantação de práticas de governança de TI: Um estudo de caso. Porto Alegre: Universidade Federal do Rio Grande do Sul, 2010. Disponível em: http://www.lume.ufrgs.br/handle/10183/29738. Acesso em: 10 nov. 2017.

MULLER, F. M. Plano Diretor de Tecnologia da Informação - PDTI 2012-2013. Santa Maria: UFSM, 2013. Disponível em: http://site.ufsm.br/arquivos/uploaded/arquivos/2e8b6eb1-ffb1-4afe-8b3d-4980ef62de3.pdf. Acesso em: 01 out. 2017.

NEVES, R. T. Gerenciamento de problemas a luz da ITIL v3: Implantando a gestão por meio do software open ticket request system. 2013. TCC (Graduação) - Serviço Nacional de Aprendizagem Comercial - Brasília, DF, 2013. Disponível em: https://ecitydoc.com/download/gerenciamento-de-problemas-a-luz-da-itil-v3implantando-a-gestao_pdf. Acesso em: 01 out. 2017.

RAPOSO, M.; LEITÃO, J.; PAÇO, A. E-governance and public marketing tools for universities: a benchmarking proposal. International Review on Public and Non-Profit Marketing, v. 3, n. 2, p. 25-40, 2006.

RODRIGUES, M. V. R. Governança de TI no setor público: caso Dataprev it governance. [2005]. Disponível em: http://www.kmpress.com.br/site/wp-content/uploads. Acesso em: 25 mar. 2017.

YIN, R. K. Estudo de Caso: planejamento e métodos. 2. ed. Porto Alegre: Bookman, 2001. 